\title{
The NMDA Receptor Antagonist D-2-amino-5-phosphonopentanoate (D-AP5) Impairs Spatial Learning and LTP in vivo at Intracerebral Concentrations Comparable to Those that Block LTP in vitro
}

\author{
S. Davis, S. P. Butcher, and R. G. M. Morris \\ Department of Pharmacology, University of Edinburgh Medical School, Edinburgh EH8 9JZ, Scotland
}

This series of experiments investigated whether the NMDA receptor antagonist D-2-amino-5-phosphonopentanoate (DAP5) could induce impairments of spatial learning across a dose range comparable to its impairment of hippocampal long-term potentiation (LTP) in vivo. Estimations of the extracellular concentration of D-AP5 in hippocampus using microdialysis were also made to compare whether these impairments occur at concentrations similar to those required to impair LTP in the in vitro hippocampal slice. Rats were chronically infused with D-AP5 into the lateral ventricle at a range of concentrations (0-50 mM) via osmotic minipumps. They were first trained to find and escape onto a hidden platform in an open-field water maze task. After the behavioral learning, they were anesthetized with urethane and an attempt was made to evoke and monitor hippocampal LTP. Extracellular samples of D-AP5 in hippocampus were then taken using microdialysis, and finally, the animals were killed and tissue samples dissected. The microdialysis and tissue samples were analyzed for D-AP5 content using HPLC with fluorescence detection. The results established, first, that D-AP5 impairs spatial learning in a linear dose-dependent manner, highly correlated with its corresponding Impairment of hippocampal LTP in vivo. No concentration of D-AP5 was observed to block LTP without affecting learning. Second, the microdialysis estimates indicated that, subject to certain assumptions, D-AP5 causes these impairments at extracellular concentrations comparable to those that impair LTP in vitro. Third, comparison of the whole tissue and microdialysis samples revealed a concentration ratio of approximately $30: 1$, indicating that $97 \%$ of the intracerebral D-AP5 is inaccessible to the dialysis probes. Infusion of $20 \mathrm{~mm}$ EGTA was found to cause a sevenfold increase in D-AP5 in the dialysis perfusates, suggesting that at least part of the inaccessible D-AP5 is trapped by a calcium-dependent mechanism. Two further behavioral control studies indicated that the D-AP5-induced impairment of spatial learning is unlikely to be secondary to a drug-induced motor disturbance, and that the performance of the D-AP5 group whose

\footnotetext{
Received Apr. 2, 1991; revised July 16, 1991; accepted July 25, 1991.

This work was supported by a grant from the Wellcome Trust (S.D.) and an MRC Programme Grant held by R.G.M.M. and D. J. Willshaw. S.P.B. is a Royal Society University Research Fellow. We are grateful to L. E. Jarrard for assistance with the ibotenate HPC lesions, Miss Elma Forrest for assistance with histology, Caroline Stewart for preparing the figures, and Rosanna Maccagnano for typing the manuscript.

Correspondence should be addressed to Dr. S. Davis, Division of Neural Systems, Memory and Aging, Life Sciences North Building, University of Arizona, 'ucson, AZ 85724.

Copyright (C) 1992 Society for Neuroscience $0270-6474 / 92 / 120021-14 \$ 05.00 / 0$
}

concentration was just sufficient to block hippocampal LTP completely was statistically indistinguishable from that of a group of rats with bilateral hippocampal lesions induced by ibotenic acid. Taken together, these findings offer support for the hypothesis that activation of NMDA receptors is necessary for certain kinds of learning.

The NMDA receptor is a subtype of excitatory amino acid receptor widely distributed throughout the mammalian CNS (Monaghan and Cotman, 1985). Two distinctive properties of the receptor, that it is both ligand and voltage gated (Engberg et al., 1979; MacDonald et al., 1982; Mayer et al., 1984; Nowak et al., 1984) and that its associated ionophore is more permeable to $\mathrm{Ca}^{2+}$ than to $\mathrm{Na}^{+}$and $\mathrm{K}^{+}$(Dingledine, 1983; Mayer and Westbrook, 1987), have each provoked particular interest among those concerned with its role in normal physiological function. The NMDA receptor has, for example, been implicated in the induction of hippocampal long-term potentiation (LTP) (Collingridge et al., 1983; Harris et al., 1984) and, more recently, in a variety of mechanisms including the coordination of rhythmic movements such as swimming (Dale, 1986, 1989), sensory transduction (Fox et al., 1989; Sillito et al., 1990), developmental plasticity (Bear et al., 1987; Kleinschmidt et al., 1987; McDonald and Johnston, 1990; Singer, 1990); and learning (Morris et al., 1986). Its highest density, however, is in the hippocampus (Monaghan et al., 1983; Monaghan and Cotman, 1985), an area associated with certain forms of learning (O'Keefe and Nadel, 1978; Olton et al., 1979; Squire, 1987). This article investigates the possible role of NMDA receptors in a type of learning known to depend on the integrity of the hippocampal formation.

Morris et al. (1986) showed that chronic infusion of the NMDA receptor antagonist DL-2-amino-5-phosphonopentanoate (DLAP5) into the right lateral ventricle causes an apparent selective impairment of learning: spatial learning is impaired, whereas visual discrimination remains unaffected. This dissociation implies that the spatial deficit is unlikely to be secondary to a gross disturbance of vision, movement, or motivation. Subsequent work has established that the behavioral selectivity of the impairment is unlikely to be due to differential drug diffusion through the brain (Butcher et al., 1991), raising the possibility that activation of NMDA receptors is required for some but not all types of learning. Competitive NMDA antagonists such as AP5, 2-amino-7-phosphonoheptanoic acid (AP7), and 3-(2-carboxypiperazin-4-yl)propyl-1-phosphonic acid (CPP) impair other spatial tasks (Danysz et al., 1988; Ward et al., 1990) and certain nonspatial tasks known to be affected by lesions of the hippocampus (Tonkiss et al., 1988; Crooks et al., 1989). Local mi- 
croinfusion of AP5 directly into the hippocampus is also sufficient to impair spatial learning (Morris et al., 1989).

The focus of this study is on one neurobiological mechanism through which NMDA receptors might be involved in learning. It is well established that their activation is essential for the induction of hippocampal LTP in vitro (Collingridge et al., 1983; Harris et al., 1984). Furthermore, there is a growing body of evidence that the mechanisms underlying LTP may be activated during (Sharp et al., 1985), and required for (McNaughton et al., 1986; Castro et al., 1989), certain types of learning. A critical test of this idea is to establish whether the NMDA receptor antagonist-induced impairment of, for example, spatial learning occurs across a dose range equivalent to that required to block the induction of LTP in vivo. The finding by Morris et al. (1986) that spatial learning is impaired by a concentration of AP5 sufficient to block LTP in vivo leaves open the possibility that the dose-response profiles of AP5's effects on LTP and spatial learning differ and, more specifically, that a concentration could be found to block LTP completely but not affect spatial learning. Such a result would severely compromise the hypothesis that activation of the neural mechanisms underlying LTP is required for such learning. Furthermore, as most work on NMDA receptor mechanisms has been carried out using in vitro preparations, it is important to assess whether the impairments in learning and LTP found in vivo occur across a dose range equivalent to those known to antagonize NMDA receptors in vitro.

To accomplish these aims, rats were implanted with minipumps containing a range of concentrations of AP5 and subjected to both hehavioral and electrophysiological testing. Levels of AP5 both in hippocampal whole tissue and in the interstitial space of the hippocampus (sampled by microdialysis) were measured using HPLC with fluorescence detection. These measures allowed animals to be classified into groups (tissue levels) and a comparison made with concentrations of AP5 used in in vitro studies (microdialysis samples). Analysis of various other amino acids (aspartate, glutamate, glutamine, taurine, valine, and alanine) was also performed in both the whole tissue and the dialysates to examine the possibility that AP5 may affect transmitter release, metabolism of amino acids, and/or the chemical balance of the extracellular fluid (ecf), any of which might be responsible for or at least contribute to the drug-induced behavioral impairments. Behavioral control studies were also carried out to compare the effects of AP5 with those of ibotenic acid-induced hippocampal lesions and to investigate whether the drug caused any performance impairment when spatial learning was prevented.

A preliminary report of parts of this work has been published elsewhere (Morris et al., 1990a).

\section{Materials and Methods}

\section{Subjects}

Male Lister-hooded rats (250-350 gm) from breeding stock in the Department of Pharmacology, University of Edinburgh, were used. They were housed individually and had free access to food and water at all times except for $12 \mathrm{hr}$ prior to surgery. They were maintained on a light/dark cycle of 14:10 hr with lights on at $0800 \mathrm{hr}$. The animals' weights were recorded from the day of surgery until the end of the experiment.

\section{Apparatus}

Behavioral testing. This was conducted using an open-field water maze (Morris, 1981, 1984) consisting, briefly, of a large circular tank $(2.0 \mathrm{~m}$ diameter) of water (depth, $0.3 \mathrm{~m}$; temperature, $25 \pm 1^{\circ} \mathrm{C}$ ) made opaque with the addition of a small quantity of milk powder. An escape platform $(10 \mathrm{~cm}$ diameter), usually in a fixed location over days, was submerged $1 \mathrm{~cm}$ below the water surface. Prominent extramaze cues were placed around the testing room to enable the animals to learn the platform's location.

The animals' swimming behavior was monitored by a video tracking system. A camera was fixed directly above the pool in a position where its entire surface area could be viewed. An appropriate level of diffuse lighting was created $(4 \times 500 \mathrm{~W}$ halogen floor-mounted floodlights angled toward the corners of the ceiling) to allow the black heads of the rats to be detected against the white water of the pool by an image analyzer (HVS, model VP112). Signals of the rats' positions from the image analyzer were sampled at a rate of $10 \mathrm{~Hz}$ and relayed to a BBC or Archimedes microcomputer, where they were stored on disk as $\mathrm{x}-\mathrm{y}$ coordinates. A video recorder (Sony Betamax) was connected between the camera and image analyzer to allow trials to be recorded on videotape and analyzed off line if necessary. A computer program analyzed the $x$-y coordinates to obtain (1) latency to find the platform (all trials), (2) swim path, (3) path length, and (4) time spent in each "quadran"" of the pool (selected trials). The quadrants analysis, used in transfer tests, is explained below.

Electrophysiological testing. This was conducted under urethane anesthesia in a Kopf stereotaxic frame using standard stereotaxic techniques. The animal's temperature was maintained at $35-37^{\circ} \mathrm{C}$ by a thermostatically controlled blanket (Harvard Apparatus). Teflon-coated stainless steel stimulating and recording electrodes were implanted to record positive-going field potentials from the hilus of the dentate gyrus. Electrical stimulation was controlled by a Neurolog system capable of delivering either single pulses or trains of pulses via a stimulus isolator. Monophasic stimulation was used throughout. Field potentials were amplified 100-500 times using a Grass Instruments wide-band preamplifier (filter settings at $1-10 \mathrm{kHz}$ ) and monitored using a MINC 11/ 23 computer. The computer program sampled potentials delivered at a rate of $0.1 \mathrm{~Hz}$ and measured the early rising slope using linear regression between two defined time points (1.9-2.6 msec, depending on the potential).

Microdialysis. Dialysis probes for sampling extracellular levels of AP5 and amino acids in the hippocampus (AP $=-5.8 \mathrm{~mm}, \mathrm{ML}=5.2 \mathrm{~mm}$, $\mathrm{DV}=-7.6 \mathrm{~mm}$ from brain surface) consisted of two plastic-coated vitreous silica tubes (VS 170/110, Scientific Glass Engineering) inserted into a 5-6 mm length of dialysis tubing (Cuprophan, B4AH, Cobo Medical) with a molecular weight cutoff of $5000 \mathrm{Da}$ (Sandberg, 1986). The probes were assembled with the aid of a low-powered binocular microscopc. The two picces of silica tubing were staggered to provide a $3 \mathrm{~mm}$ length of active dialysis membrane. Artificial cerebrospinal fluid (aCSF) was pumped into one length of tubing and collected from the outlet of the other piece. A length of Teflon-coated electrode wire (WT3, Clark Electromedical Instruments) was inserted the full length of the dialysis membrane to provide rigidity. Both ends of the probe were sealed with cyanoacrylate adhesive, and it was then placed in a protective metal casing ( 21 gauge stainless steel tubing) positioned 10 $\mathrm{mm}$ above the dialysis membrane while held in the stereotaxic manipulator. Narrow-bore polyethylene tubing was glued around the inlet silica capillary and connected to a syringe mounted in a constant-drive microinfusion pump (Carnegie Medicine, CMA 100) that pumped aCSF through the probe at a rate of $1.25 \mu \mathrm{l} / \mathrm{min}$.

\section{Drug concentrations, surgery, amino acid analysis, and histology}

All drugs and anesthetics were made up in deionized water except in a final replicate when they were made up in pyrogen-free water. An equivalent stock concentration of $100 \mathrm{~mm}$ D-AP5 was made up in $100 \mathrm{~mm}$ $\mathrm{NaOH}$ and kept as frozen aliquots. This was diluted with aCSF (Alza methodology) for a range of concentrations $(5,13,20,30,40$, and 50 m. "spiked" with $\mathrm{NaOH}$ to maintain a $\mathrm{pH}$ of 7.4. Stock solution of EGTA (500 mM) was made up as an equivalent in $\mathrm{NaOH}$ and diluted to $20 \mathrm{~mm}$ with $\mathrm{Ca}^{2+}$-free aCSF (Alza methodology). Ibotenic acid was dissolved in phosphate-buffered saline $(\mathrm{pH} 7.4)$ at a concentration of $10 \mathrm{mg} / \mathrm{ml}$

As AP5 does not cross the blood-brain barrier, it was delivered to the brain by chronic infusion using osmotic minipumps (Alza model 2002; pumping rate, $0.5 \mu \mathrm{l} / \mathrm{hr}$ ). Animals were placed in a Kopf stereotaxic apparatus to implant the minipumps under tribromoethanol ancsthesia $(0.29 \mathrm{gm} / \mathrm{kg})$. An incision was madc along the midlinc, the skull was exposed, and an L-shaped stainless steel cannula (23 gauge) was 
placed in the left lateral ventricle (AP $=-0.9, \mathrm{ML}=1.3, \mathrm{DV}=-4.5$ from skull surface). The cannula was attached to the minipump with Silastic tubing and secured in place with dental acrylic and three watchmaker's screws. The minipump was placed in the subcutaneous pocket extending from the caudal end of the incision to the shoulder blades. The scalp incision was closed with discontinuous suture, and animals were allowed 2 d postoperative recovery. During the surgery, positions were marked on the skull for the microdialysis probe and the two electrodes.

For the ibotenic acid lesions, animals were placed in a stereotaxic frame and anesthetized with tribromoethanol. Animals were lesioned according to the methodology devised by Jarrard (1989) using ibotenic acid (either 0.05 or $0.10 \mu 1$ ) at 26 sites bilaterally and allowed 2 weeks recovery before behavioral testing.

Analysis of AP5 and amino acids in both brain tissue and dialysis samples was carried out using a Varian Vista 5500 pumping system 9090 automatic column injector, and a $5 \mu \mathrm{m}$ Nucleosil C-18 column $(250 \times 4.6 \mathrm{~mm})$. Separation of amino acids was achieved with a gradient eluent using a phosphate buffer [buffer A: $50 \mathrm{~mm}$ and tetrahydrofuran (THF) (2.5\%); pH 5.12] with an organic modifier, methanol [buffer B and THF (1.25\%)]. The gradient profilc with a pumping rate of $1 \mathrm{ml} /$ min was as follows: [time (min), \%B] 0, 0; 5, 0; 7, 25; 15, 50; 23, 60; 25,$90 ; 28,110 ; 32,100 ; 42,0$. Precolumn derivatization with $o$-phthaldehyde (Lindroth et al., 1985) allowed detection of primary amino acids by fluorescence, using an ABS 980 fluorescence detector (excitation wavelength, $230 \mu \mathrm{m}$; emission wavelength, $>398 \mu \mathrm{m}$ ). A standard containing known quantities of amino acids and AP5 was injected onto the column at the start and end of each daily session of analysis to calibrate retention time and peak area of each molecular component measured. Data were integrated and quantified using a microcomputer-based integration package (Midas, Comas Instruments).

The animals were killed at the end of the experiment, and their brains were removed on ice. Tissue from the right and left hippocampus of animals in the dose-response study was dissected out and kept in frozen storage $\left(-20^{\circ} \mathrm{C}\right)$ for analysis of AP5 and amino acid content. Tissue from the region immediately adjacent to the infusion cannula was retained in formalin, frozen, cut into $30 \mu \mathrm{m}$ coronal sections, and stained with fast cresyl violet. This allowed verification of the cannula position and assessment of any damage caused by it and/or by drug infusion. The brains from the hippocampally lesioned animals were embedded in egg yolk, frozen, and cut into $30 \mu \mathrm{m}$ horizontal sections to assess the extent of cell loss.

\section{Experiment 1: the dose-response profile of chronic intracerebral infusion of AP5 upon spatial learning and the induction of LTP in vivo}

The experiment was run in replicates, each consisting of up to 12 animals and lasting a period of $17 \mathrm{~d}$. Each replicate included rats in the control group (consisting of aCSF-infused, shamlesioned, and/or unoperated rats) and rats given minipumps containing AP5 at one of at least two concentrations. Data were analyzed from the final total of 73 animals from which tissue samples were obtained (but see below where smaller data sets were used for some analyses). The cxperimental design is summarized in Figure 1.

\section{Phase 1: behavioral procedure}

All animals were first given 12 trials of nonspatial pretraining over $3 \mathrm{~d}(4 \mathrm{trials} / \mathrm{d})$ in the water maze. Curtains were drawn around the pool to occlude extramaze cues, and the platform position was moved to a new location on each trial. A maximum swim time of $120 \mathrm{sec}$ was allowed with a $30 \mathrm{sec}$ intertrial interval (ITI) on the platform. Latencies were recorded using a stopwatch.

The minipumps were then surgically implanted and, following recovery ( $3 \mathrm{~d})$, the animals were given spatial training consisting of six trials/day for $5 \mathrm{~d}$ with a fixed platform placed in the center of one of the four quadrants of the pool (NW, SE, SW, NE). Animals were placed in the water at one of the four N, S, E, or

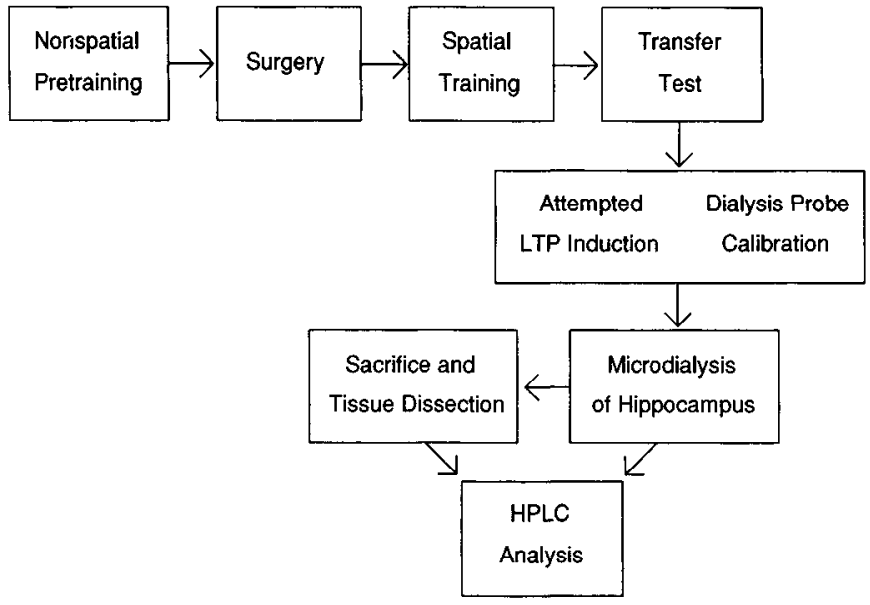

Figure 1. Summary of experimental design. See text for detailed explanation of each phase.

W start positions chosen randomly across trials. The maximum swim time was again $120 \mathrm{sec}$ with a $30 \mathrm{sec}$ ITI on the platform. A transfer test was given immediately after the last trial on day 5. For this test, the platform was removed from the pool and the animals allowed to swim freely for $60 \mathrm{sec}$. The time spent in each of the four quadrants was computed using the automatic tracking system. Testing took place between 0800 and $1800 \mathrm{hr}$ each day.

\section{Phase 2: electrophysical procedure}

$\Lambda \mathrm{fter}$ behavioral testing, the attempt to evoke LTP in each individual animal was made on one of the next 4 days. Anesthetized animals were placed in the stereotaxic frame and implanted with Teflon-coated stainless steel stimulating and recording electrodes. The stimulating electrode was lowered into the angular bundle of the perforant path (AP $=-8.0 \mathrm{~mm}, \mathrm{ML}$ $=4.1 \mathrm{~mm}$ ) to a depth of $2.8 \pm 0.2 \mathrm{~mm}$. The recording electrode aimed at the hilus of the dentate gyrus (AP $=-3.5 \mathrm{~mm}, \mathrm{ML}$ $=2.0 \mathrm{~mm}$ ) was first lowered to a depth of $1.5 \mathrm{~mm}$. From this position, just above the CAl pyramidal cell layer, it was subsequently stepped down in $0.1 \mathrm{~mm}$ steps. Potentials were checked on the oscilloscope at each step, and the final depth of the recording electrode was generally $3.1 \pm 0.2 \mathrm{~mm}$. After optimum adjustment of the electrodes, a minimum period of $30 \mathrm{~min}$ was allowed for the tissue to settle, with low-frequency stimulation delivered to measure baseline stability. When a stable baseline had been attained, the main series of testing was started. Lowfrequency stimulation $(0.1 \mathrm{~Hz}, 0.1 \mathrm{msec}, 700 \mu \mathrm{A})$ was delivered for $10 \mathrm{~min}$ as a pretetanus baseline. A high-frequency tetanus was then given (three "trains" of 33 pulses at $400 \mathrm{~Hz}$ at $10 \mathrm{sec}$ intervals), after which the stimulation was returned to low frequency again with potentials recorded for a further $50 \mathrm{~min}$.

\section{Phase 3: microdialysis sampling of the ecf in hippocampus}

Following the attempt to evoke LTP, the microdialysis probe was lowered into the left hippocampus to estimate the ecf level of D-AP5 and six amino acids. Once in situ, the probe was connected to the microinjection pump and aCSF was infused through the probe at a rate of $1.25 \mu \mathrm{l} / \mathrm{min}$. After a $60 \mathrm{~min}$ washout period, six $20 \mathrm{~min}$ dialysate samples were collected and kept in frozen storage for later analysis.

In the final replicate, microdialysis probes were calibrated for 


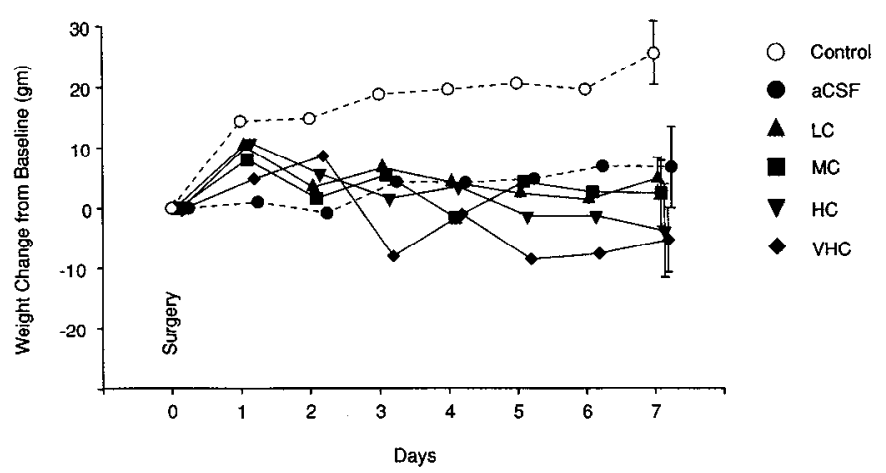

Figure 2. Change in weight (gm \pm 1 SEM) of the animals from their weight on the day of surgery (preceded by $24 \mathrm{hr}$ water deprivation). The unoperated control and sham-operated rats are treated as a single "control" group while the aCSF control animals are here (only) considered as a separate group. Control and aCSF rats are considered as a single control group in all remaining figures. Note that infusion of aCSF itself causes a failure to gain weight over the course of $7 \mathrm{~d}$ following surgery.

the amount of AP5 transported across the membrane. Two 20 min samples of fluid were taken from probes placed in a beaker containing $5 \mu \mathrm{M}$ AP5. A mean recovery rate of $6.2 \%$ at $1.25 \mu \mathrm{l} /$ min was obtained across a sample of 12 probes with minimal variability. Using this recovery rate, the "effective" extracellular concentration of AP5 could be estimated from the concentrations measured in the dialysate samples (true concentration $=$ dialysate concentration/recovery rate). There are several sources of inaccuracy in making such an estimate, of which the greatest is likely to be a systematic discrepancy between dialysis efficiency in a solution in vitro and that obtained in vivo. Our calculations of extracellular concentration are therefore referred to as "estimated" concentrations. A detailed theoretical treatment of relevant issues may be found in Benveniste (1989).

\section{Tissue sampling}

When the dialysis sampling was completed, the animals were killed and their brains removed on ice. Whole tissue from the right and left hippocampus was taken for measurement of AP5 content and for comparison with the dialysates. Tissue was prepared for HPLC analysis by homogenization in $1.0 \mathrm{ml}$ of perchloric acid $(0.6 \mathrm{M})$ to precipitate tissue protein. The homogenate was kept at $-4^{\circ} \mathrm{C}$ overnight and then centrifuged at 10,000 $g$ for $2 \mathrm{~min}$. The supernatant was neutralized in potassium bicarbonate $(2.0 \mathrm{M})$ and centrifuged again at $10,000 \mathrm{~g}$ for $2 \mathrm{~min}$. This preparation was diluted 1:10 with deionized water and injected onto the HPLC column.

\section{Results}

Assignment of animals to groups

The optimal data set consisted of results from the behavioral and electrophysiological phases together with measurements of AP5 and amino acids in both hippocampal whole tissue and microdialysis samples. In practice, not all animals contributed an entire data set due to either unquantifiable data (e.g., unstable baselines during electrophysiological recording) or, in the case of some animals, death under urethane anesthesia during the electrophysiological or microdialysis phases. For any data from any individual animal to be accepted, it was decided that a quantified measure of the amount of AP5 in the combined whole tissue from the right and left hippocampus ( $\mathrm{nmol} / \mathrm{mg}$ wet weight) had to be obtained. This measure of whole-tissue AP5 levels formed the basis for grouping animals. Specifically, animals were grouped into Control (CTL), low (LC), mid (MC), high (HC), or very high (VHC) concentration groups if their AP5 tissue levels were either 0 or fell between the arbitrary boundaries of $0.01-0.10,0.11-0.20,0.21-0.30$, or above $0.31 \mathrm{nmol} /$ $\mathrm{mg}$ wet weight, respectively. This yielded 73 animals in the behavioral phase and 65 in the electrophysiological phase. The amino acid analysis was carried out on all of these animals. Correlations were, however, carried out only on (1) those animals from which data had been obtained from all three phases of the experiment (i.e., behavioral, electrophysiological, and dialysis phases), and (2) animals who showed no signs of sensorimotor impairment during the behavioral phase. Specifically, a small number of animals did show signs of behavioral disturbances, such as difficulty in swimming and getting onto and/ or remaining on the platform. In the analysis of AP5 levels in hippocampal whole tissue, all of these animals showed levels of AP5 in excess of $0.31 \mathrm{nmol} / \mathrm{mg}$ wet weight (Table 1). Accordingly, the decision was taken to conduct correlational analyses on only those animals in the remaining groups that provided data from all three phases $(N=49$; see Table 1$)$.

\section{Histology}

The cannula was correctly placed in the right lateral ventricle in all animals. It necessarily caused some mechanical damage, and in some animals there were signs of ventricular enlargement. An ANOVA of escape latencies during spatial learning showed comparable performance by controls implanted with minipumps containing aCSF (mean of 30 trials $=17.8 \pm 8.7 \mathrm{sec}$ ) and both sham and unoperated animals [mean $=11.8 \pm 3.7$ sec; $F(1,11)=3.22 ; p>0.1$ ]. It was therefore concluded that neither infusion of aCSF nor direct damage to the brains of the aCSF animals caused a detrimental effect on performance. The histologically observed damage in the AP5-treated animals was comparable to that in the aCSF animals.

\section{Weights}

Water deprivation on the night before surgery caused a drop in weight. Accordingly, most animals showed a compensatory increase in body weight on the day after surgery due to their resumed consumption of both food and water. Thereafter, shamoperated animals continued to gain weight steadily over the rest of the experimental period, while animals infused with either aCSF or AP5 failed to do so (Fig. 2). An ANOVA ( $N=68$; data lost from five animals) of the change in body weight over the next $7 \mathrm{~d}$ showed that there was no overall difference between groups $[F(5,62)=1.98 ; p>0.05]$ but a significant groups by days interaction $[F(30,372)=1.67 ; p<0.02]$. Importantly, the body weights of the sham-operated and unoperated controls increased such that, by day 8 , they were significantly greater than the mean of all animals implanted with minipumps $[F(1,62)$ $=7.2 ; p<0.001]$. Despite indications of a trend, the aCSF and AP5 animals did not differ $(F<1)$. These findings imply that the presence of the minipumps and/or the pumping of a solution into the brain was causing or contributing to the failure to gain weight.

\section{Behavioral analysis}

Pretraining. The animals rapidly learned the nonspatial aspects of the task such as swimming away from the side walls, learning to use the platform as a means of escape, and staying still on it. All animals showed a significant decrease in latency to escape 


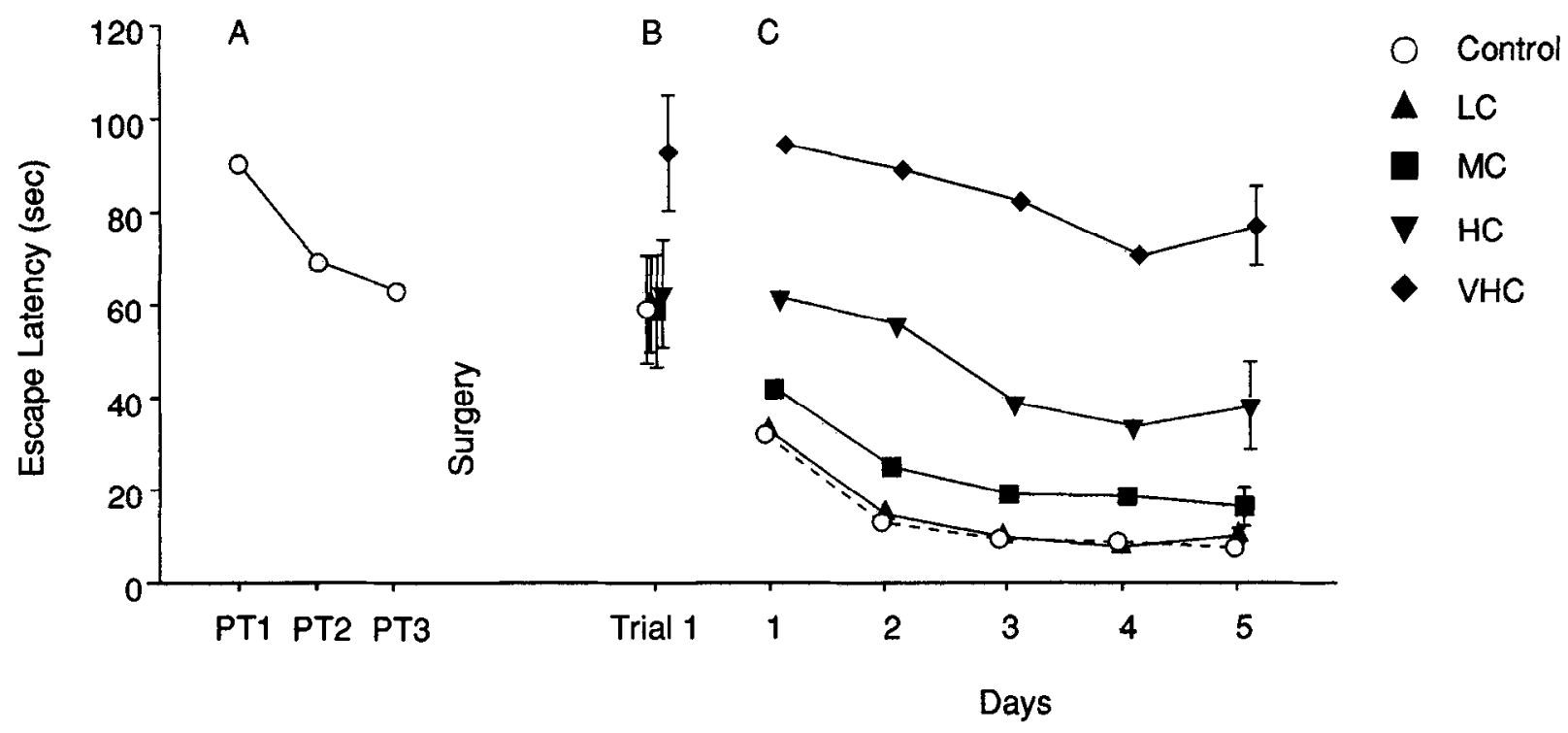

Figure 3. Escape latency ( $\mathrm{sec} \pm 1 \mathrm{SEM}$ ) across the various stages of the behavioral phase of Experiment $1 . A$, Mean nonspatial pretraining latency across all animals. Surgery (minipump implantation) was carried out on the day following the third pretraining day $(P T 3)$. $B$, Escape latency on the first spatial training trial prior to any possible spatial learning. Note all groups except group VHC have equivalent escape latencies. $C$, Doserelated impairment of escape latency over the $5 \mathrm{~d}$ (30 trials) of spatial training.

the water across trials $[F(11,792)=10.37 ; p<0.001]$ to a mean level of $75.1 \pm 5.1 \mathrm{sec}$ on the last trial (Fig. $3 A$ ).

Acquisition. All animals except those in the VHC group performed the spatial task well by swimming to the platform and climbing onto it. Importantly, there was a clear qualitative indication of a drug-induced impairment of spatial learning across groups. In the VHC group only, there were also signs of prolonged sensorimotor disturbance characterized by enhanced thigmotaxis, an inability to climb onto and remain on the platform, and impaired righting reflexes. The VHC group also slowed very extended escape latencies.

On the first trial of spatial training, all animals escaped the water in an average of $60.2 \pm 9.8 \mathrm{sec}$, except those of the VHC group, which took $92.7 \pm 12.9 \mathrm{sec}$ (Fig. $3 B$ ). An ANOVA showed that this difference in first trial latency was significant $[F(1,71)$ $=5.49 ; p<0.025$ ]. Over the next $5 \mathrm{~d}$ of training, the CTL animals learned the location of the platform rapidly and escaped the water with decreasing latencies (Fig. $3 C$ ). By the end of the fifth day, they were escaping the water in $8.1 \pm 1.2 \mathrm{sec}$, taking direct paths to the platform from any start location. In comparison, the AP5-treated groups showed a dose-related impairment. An ANOVA of escape latencies showed an overall difference between groups $[F(4,68)=45.95 ; p<0.001]$, with no groups by day interaction $(F<1)$. Subsequent orthogonal comparisons established that CTL animals were consistently escaping the water more rapidly than the AP5-infused animals $[F(1,68)$ $=30.7, p<0.001]$, with the LC group being indistinguishable from the CTL group and the higher-concentration groups show-

Table 1.

\begin{tabular}{|c|c|c|c|c|c|c|c|c|c|c|}
\hline \multirow[b]{3}{*}{ Groups $^{\alpha}$} & \multirow{2}{*}{\multicolumn{4}{|c|}{ Behavioral data }} & \multicolumn{6}{|c|}{ Electrophysiological data } \\
\hline & & & & & \multirow[b]{2}{*}{$N^{c}$} & \multirow[b]{2}{*}{$\begin{array}{l}\text { AP5 } \\
\text { concentration } \\
\text { (nmol/mg) }\end{array}$} & \multirow[b]{2}{*}{$\begin{array}{l}\text { LTP } \\
\text { (\% slope) }\end{array}$} & \multirow[b]{2}{*}{$\begin{array}{l}\text { Slope } \\
\text { (mV/ } \\
\text { msec) } \\
\end{array}$} & \multirow[b]{2}{*}{$\begin{array}{l}\text { Amp } \\
(\mathrm{mV})\end{array}$} & \multirow[b]{2}{*}{$\begin{array}{l}\text { PTP/ } \\
\text { STP } \\
(1 / 2 \\
\text { decay })^{d}\end{array}$} \\
\hline & $N$ & $\begin{array}{l}\text { AP5 } \\
\text { concentration } \\
\text { (nmol/mg) }^{b}\end{array}$ & $\begin{array}{l}\text { Latency } \\
\text { (sec) }\end{array}$ & $\begin{array}{l}\text { T test } \\
\text { (\% time) }\end{array}$ & & & & & & \\
\hline \multicolumn{11}{|l|}{ Control } \\
\hline$(0.00)$ & 13 & 0.00 & 14.7 & 58.1 & 13 & 0.00 & 21.9 & 2,9 & 9.3 & 341 \\
\hline \multicolumn{11}{|l|}{$\mathrm{LC}$} \\
\hline$(0.01-0.10)$ & 20 & $0.06 \pm 0.02$ & 14.6 & 59.4 & 14 & $0.06 \pm 0.03$ & 20.4 & 3.9 & 10.2 & 155 \\
\hline \multicolumn{11}{|l|}{ MC } \\
\hline$(0.11-0.20)$ & 13 & $0.15 \pm 0.03$ & 24.2 & 53.7 & 13 & $0.15 \pm 0.03$ & 8.2 & 3.1 & 9.1 & 139 \\
\hline \multicolumn{11}{|l|}{$\mathrm{HC}$} \\
\hline$(0.21-0.30)$ & 16 & $0.27 \pm 0.03$ & 45.6 & 41.4 & 14 & $0.27 \pm 0.03$ & -1.2 & 4.9 & 11.4 & 74 \\
\hline \multicolumn{11}{|l|}{ VHC } \\
\hline$(>0.31)$ & 11 & $0.44 \pm 0.09$ & 82.7 & 26.6 & 11 & $0.44 \pm 0.09$ & 1.4 & 4.6 & 10.5 & 70 \\
\hline
\end{tabular}

${ }^{a}$ Rats were assigned to groups based on their mean hippocampal whole-tissue concentration (shown as nmolmg wet weight).

${ }^{h}$ Group mean hippocampal whole-tissue concentration \pm 1 SEM.

- Note that numbers of animals are different in two of the groups.

${ }^{d}$ Half-decay time of short-term potentiation in seconds. 
Transfer Test

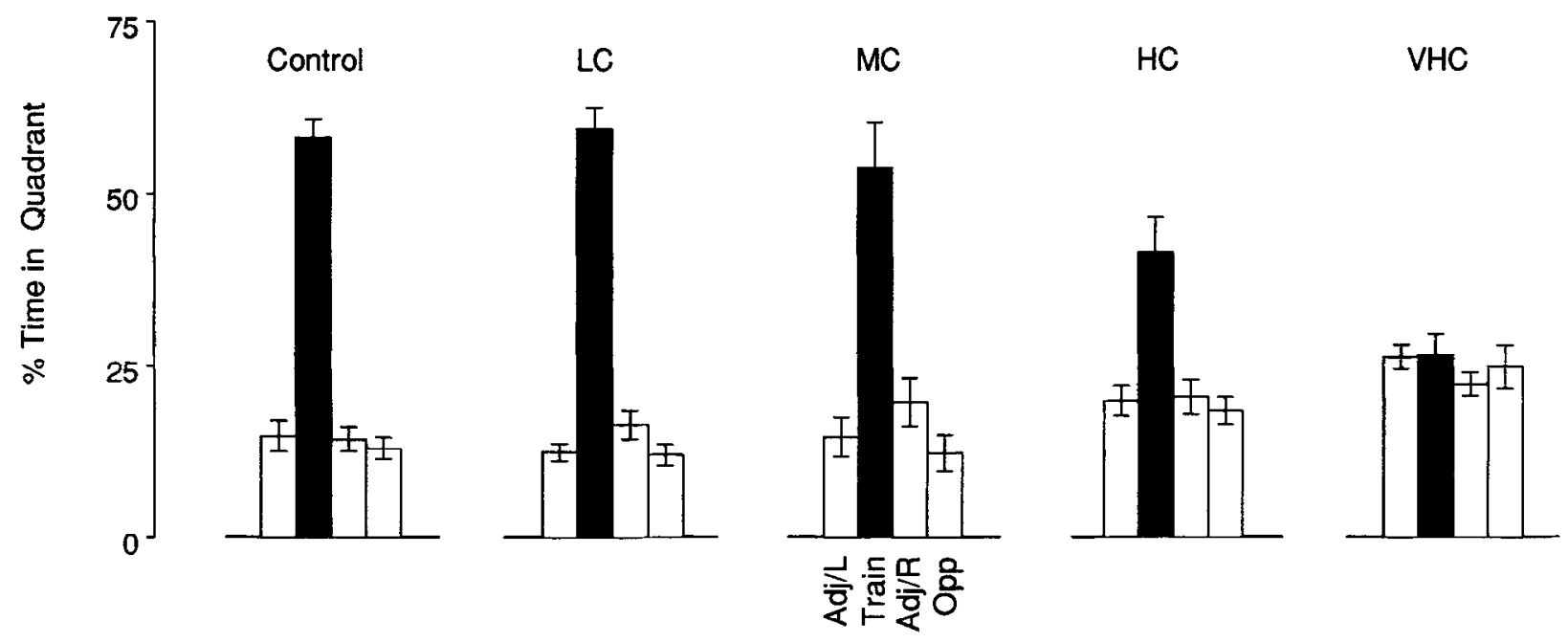

Figure 4. Transfer test performance (\% time in each quadrant $\pm 1 \mathrm{SEM}$ ) across all groups on the test (no platform present) conducted immediately after trial 30. Note dose-related impairment.

ing a severe impairment (Fig. $3 B$ ). Furthermore, the AP5 groups showed a significant linear effect of dose $\left[F_{\operatorname{lin}}(1,68)=57.4 ; p<\right.$ $0.001]$.

A further feature of the behavioral data (not shown) concerned how escape latency changed within each series of six daily trials. In addition to the changes across days, the overall analysis also showed a highly significant groups by trials interaction $[F(20,340)$ $=4.57, p<0.001]$. Inspection of the relevant data indicated that, averaged across all $5 \mathrm{~d}$ of training, the CTL animals improved across their daily trials while the VHC group apparently got worse. Separate analyses were therefore carried out to compare performance on the first and last trials of the day for each group. These showed that CTL, LC, and MC groups improved across trials ( $p$ values of $<0.01,<0.001,<0.01$, respectively), the HC group showed no change $(p>0.20)$, and the VHC group was in fact taking longer to escape the water by the end of each day $(p<0.05)$. One interpretation of these findings is that poor performance on early trials results in the animals becoming tired and this, in turn, cxacerbates their drug-induced impairment. However, for this interpretation to be valid, it was essential to establish that there was a drug-induced impairment on the first trial of each day. Accordingly, a separate analysis was carried out on each of these trials only, and it showed a highly significant dose-related impairment $[F(4,68)=12.45 ; p<0.001]$.

An ANOVA was also carried out on swim speeds and path lengths to test whether the poor performance, particularly of the VHC group, could have been due to their swimming more slowly. This analysis was carried out on day 2 because there was an indication that the greatest spatial impairment occurred on this day. No significant group difference in swim speed was found $(F<1)$. A group difference in path lengths $[F(4,68)=21.17 ; p$ $<0.001]$ was found, but as expected, path length and latency were highly correlated $(r=0.83 ; \mathrm{df}=72 ; p<0.001)$.

Transfer test. Control animals swam persistently in the vicinity of the former position of the platform, spending most of their time in the training quadrant. An ANOVA of time spent in all quadrants of the pool showed a groups by quadrant interaction $[F(12,102)=7.94 ; p<0.001]$. An ANOVA carried out on the training quadrant time only also showed an overall difference between groups $[F(4,68)=10.36 ; p<0.001]$, but a Newman-Keuls test revealed that only the HC and VHC groups differed from controls ( $p<0.05$; Table 1, Fig. 4).

Correlational analysis. The final stage of the behavioral analysis was to examine the correlation, in individual animals, between AP5 tissue levels and behavioral performance. In conducting these correlations, scores of animals in the VHC group were first deleted, as these artificially inflated the correlation coeflicients by virtue of their sensorimotor disturbance and high AP5 tissue levels. Pearson product-moment correlations for the remaining 49 animals between AP5 concentration and both the mean escape latency across all 30 trials $(r=0.70 ; \mathrm{df}=48 ; p<$ $0.001)$ and time in the training quadrant during the transfer test $(r=-0.45 ; p<0.001)$ were each highly significant.

\section{Electrophysiological analysis}

$L T P$. AP5 caused a dose-dependent decrease in LTP of the field potential slope function. $\Lambda \mathrm{n} A N O V \Lambda$ of the percentage increase in slope measured $30 \mathrm{~min}$ after the tetanus (mean of 10 values) showed an overall difference between groups $[F(4,60)=17.01$; $p<0.001]$. Subsequent analysis revealed a linear decline in LTP as a function of AP5 concentration $\left[F_{\text {lin }}(1,60)=31.16 ; p\right.$ $<0.001$; Table 1 and Fig. 5].

Amplitude and slope. Under conditions of low-frequency stimulation prior to the induction of LTP, the mean field potential amplitude did not differ across groups $(F<1$; see Table 1) but the slope values did differ $[F(4,60)=3.25 ; p<0.5$; see Table 1]. A Newman-Keuls post hoc test showed that the only difference between groups was that the CTL group had lower slope values than the HC group $(p<0.05)$. This difference in mean pre-LTP slope under low-frequency stimulation complicates the interpretation of the AP5-induced blockade of LTP. Specifically, the HC group may have failed to display LTP, not because of the presence of AP5, but because its mean slope value was already at or near its asymptotic level. To investigate this possibility further, a correlation was carried out between the pre-LTP slope values and the percentage LTP in each animal 

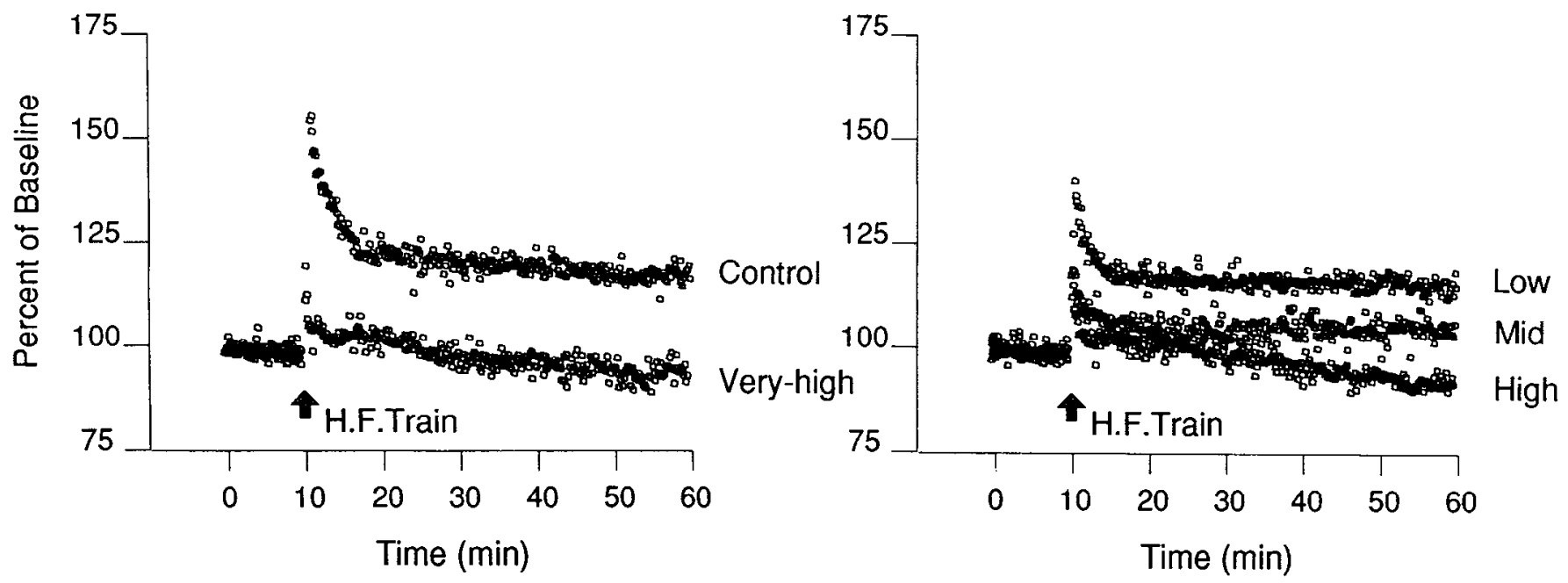

Figure 5. Attempted induction of LTP at various intracerebral concentrations of AP5. Values plotted are the mean normalized values of the early rising slope $(100 \%=$ baseline) at $10 \mathrm{sec}$ intervals throughout the experiment. Left, Control and VHC groups. Right, Dose-related impairment across the $\mathrm{LC}, \mathrm{MC}$, and $\mathrm{HC}$ groups. Note apparent reduction in short-term potentiation with increasing concentration.

of the two groups in which maximal LTP was successfully evoked-namely, the CTL and LC groups. This correlation was nonsignificant $(r=0.08 ; p>0.21)$, implying that blockade of LTP in the HC group was also unlikely to be due to its high mean slope value.

Posttetanic or short-term potentiation. Visual inspection of Figure 5 indicates that there may have been some form of druginduced decrease in posttetanic or short-term potentiation (PTP/ STP). This is also indicated by estimates of the mean half-decay times of PTP/STP across groups as follows: based on the assumption that the PTP decay rate follows a standard exponential function, 18 slope values were measured at $10 \mathrm{sec}$ intervals during the first 3 min after the tetanus in individual animals. These were normalized relative to the individual pretetanus baseline. The normalized score for the slope value at the point where PTP/STP had dccayed and LTP stabilized (i.e., $10 \mathrm{~min}$ posttetanus) was then subtracted from each of these 18 values. The natural logarithm of these values was then computed and plotted against time using linear regression. The slope of this line was used to calculate half-decay times. The results (Table 1) indicate that all groups showed PTP/STP, but compared with the CTL group, even low concentrations of AP5 reduced its amount and increased its rate of decay.

Correlational analysis. As before, rats of the VHC group were deleted from the correlational analysis. This analysis nevertheless showed a highly significant correlation between AP5 tissue levels and LTP 30 min posttetanus $(r=-0.72$; df $=48 ; p<$ $0.001)$. Furthermore, when behavioral performance was correlated with LTP across individual animals, highly significant correlations were found for both escape latency $(r=-0.62$; $\mathrm{df}$ $=48 ; p<0.001)$ and transfer test performance $(r=0.45 ; p<$ $0.001)$.

The results presented above show dose-related impairments of spatial learning and LTP as well as highly significant correlations between AP5 tissue levels and performance in each of these two phases of the experiment. An unexpected feature of the data, however, is that the absolute levels of AP5 required to elicit these effects in vivo were substantially higher than the bath concentrations of AP5 required to block LTP completely in the hippocampal slice (Harris et al., 1984). For example, the mean AP5 tissue concentration in the $\mathrm{HC}$ group was $0.27 \mathrm{nmol} /$ mg wet weight (Table 1), that is, $270 \mu \mathrm{m}$ (assuming that the brain tissue samples have a specific gravity close to 1). Harris et al. (1984) found that the $\mathrm{ED}_{50}$ for the blockade of LTP was $4 \mu \mathrm{M}$, with a complete block at $50 \mu \mathrm{M}$. This apparent discrepancy between results from the in vivo and in vitro preparations raises two questions. First, does chronic infusion of AP5 have some effect on amino acid levels that could be contributing to or even causing the learning impairment? Second, are the tissue levels of AP5 an accurate indicator of the effective extracellular concentration? These two issues will be addressed in turn.

\section{Amino acid levels}

The mean concentrations of AP5 across groups in both phases of the experiment are shown in Table 1. The tissue levels of amino acids were, however, analyzed in only those animals that had completed all three phases of the experiment (data from three animals were lost; therefore, $N=46$ ). ANOVA carried out on each of six amino acids showed that five of them did not differ across groups (mean levels in $\mathrm{nmol} / \mathrm{mg}$ wet weight: $\mathrm{Asp}=2.04, \mathrm{Glu}=7.37, \mathrm{Gln}=4.06, \mathrm{Tau}=5.36, \mathrm{Ala}=0.82$ ) while valine was significantly affected by AP5 concentration $[F(3,42)=4.60 ; p<0.01]$. Specifically, valine levels increased in a linear fashion from a level of $0.18 \mathrm{nmol} / \mathrm{mg}$ in controls to a level of $0.25 \mathrm{nmol} / \mathrm{mg}$ in the $\mathrm{HC}$ group $\left[F_{\text {lun }}(1,42)=12.8 ; p\right.$ $<0.001]$. This finding was unexpected but confirmed in a correlational analysis on individual animals - valine and AP5 tissue levels were highly significantly related $(r=0.48 ; \mathrm{df}=45 ; p$ $<0.001)$. However, valine levels were only weakly correlated with escape latency $(r=0.31 ; p<0.05)$ and not at all with the transfer test scores $(r=-0.03)$. Valine levels were, nevertheless, also strongly correlated with LTP $(r=-0.53 ; p<0.001)$.

\section{Microdialysis}

Comparison with tissue content. The second question concerned whether the tissue concentrations of AP5 were both a reliable and valid measure of D-AP5 levels in ecf. An ANOVA of the estimated extracellular concentrations (see Materials and Methods for how this was calculated) showed a highly significant increase in AP5 concentration across groups $[F(4,44)=20.3 ; p$ 


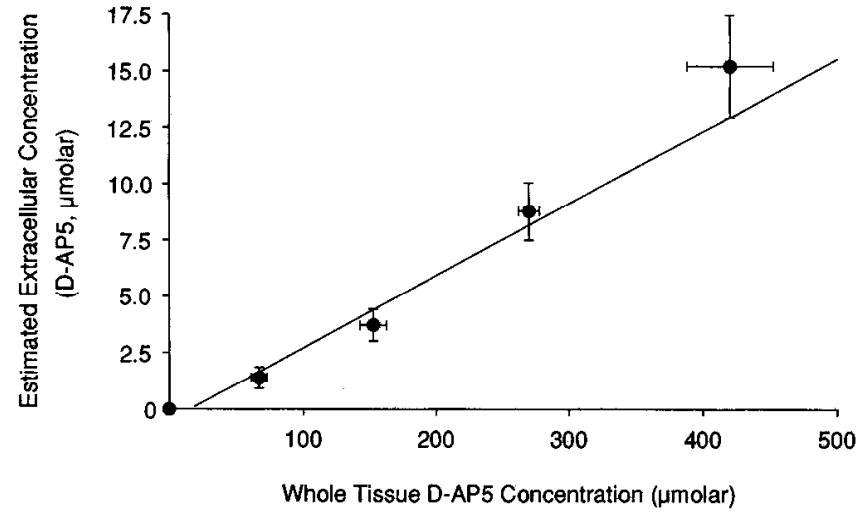

Figure 6. Relationship between whole-tissue AP5 concentration $(\mu \mathrm{M})$ and estimated extracellular concentration. The latter was calculated by assuming that the recovery rate from the microdialysis probes in brain was the same as that from the calibrating concentrations. Points plotted are means $( \pm 1$ SEM on each axis) for the five groups. The regression analysis, used to calculate the line plotted, was calculated using data points from individual animals. The slope of this line indicates there is a 30-fold difference between the whole-tissue and estimated extracellular concentrations.

$<0.001]$, rising from 0 in controls to a mean of $15.4 \mu \mathrm{m}$ in the VHC group. More importantly, comparison of whole-tissue concentration with estimated extracellular concentration showed (1) that these were highly correlated ( $r=0.80$; of $57 ; p<0.001$; this correlation analysis was the only one conducted with the VHC group included) and (2) that there was a 30:1 ratio between these concentrations (Fig. 6).

That the estimated hippocampal extracellular concentrations measured using dialysis are highly correlated with hippocampal whole-tissue concentrations is to be expected. However, the difference between these concentrations is remarkable, indicating that $97 \%$ of the AP5 in hippocampus is inaccessible to the dialysis probes and, presumably, to NMDA receptors also. This poses the question of where this whole-tissue AP5 is located. Experiments by M. Kessler (personal communication) and R. Griffiths (personal communication) indicate that AP5 neither inhibits the uptake of ${ }^{3} \mathrm{H}$-L-glutamate on the high-affinity glutamate uptake carrier nor is itself taken up. However, in response to a suggestion by J. C. Watkins (personal communication) that AP5 may instead have been bound to tissue by a $\mathrm{Ca}^{2+}$-dependent mechanism, it was decided to investigate the effects of infusing the $\mathrm{Ca}^{2+}$ chelator EGTA via the microdialysis probes.

EGTA infusion. After the normal dialysate sampling was completed, $20 \mathrm{~mm}$ EGTA was infused via the dialysis probes in a sample of 12 animals (all of which had $30 \mathrm{~mm}$ D-AP5 in their minipumps). The infusion medium was switched to a $\mathrm{Ca}^{2+}$-free aCSF containing $20 \mu \mathrm{M}$ EGTA. Analysis of the mean levels of AP5 in the two pre-EGTA samples with those during EGTA infusion revealed a significant sevenfold EGTA-induced increase in AP5 $[F(1,11)=10.39 ; p<0.01 ;$ Fig. 7$)$. An explanation for this increased AP5 in the dialysate sample will be discussed below; at this stage, it need only be noted that this finding offers grounds for greater confidence in the 30-fold discrepancy between the whole-tissue and estimated extracellular concentrations presented above.

Correlations. The final step of our analysis of Experiment 1 was to examine the relationship between the estimated extracellular concentrations of AP5 in individual animals with both

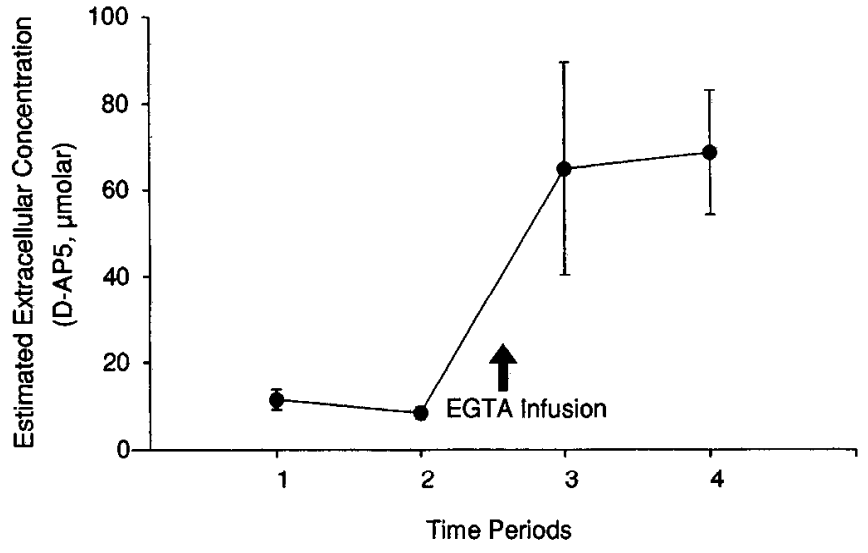

Figure 7. Release of D-AP5 upon addition of EGTA to the dialysis perfusate after two time periods $(20 \mathrm{~min}$ each) toward the end of a 2 $\mathrm{hr}$ dialysis sampling session. Note sustained release of AP5 and change in $y$-axis from Figure 6.

spatial learning and LTP. These correlations were, as in the earlier analyses, conducted after excluding the VHC group and showed that extracellular AP5 correlated with latency $(r=0.85$; of $48 ; p<0.001)$, transfer test scores $(r=-0.53 ; p<0.001)$ and LTP $(r=-0.59 ; p<0.001)$. These correlation coefficients are all very high and, in particular, indicate that extracellular AP5 concentration accounts for $72 \%$ of the variance in the latency data (Fig. 8).

\section{Experiments 2 and 3: blocking the AP5-induced impairment by preventing spatial learning and comparison of the learning deficit with that caused by hippocampal lesions}

In Experiment 1, the animals in the VHC group showed signs of sensorimotor impairment. Although the $\mathrm{HC}$ and $\mathrm{MC}$ groups did not show these signs overtly, a subtle and cryptic motor disturbance (e.g., a slowing of movement initiation) may have contributed to the impairment of spatial learning. To test for this possibility, Experiment 2 was designed to investigate whether any AP5-induced impairment remained when spatial learning was prevented. If AP5 causes a strictly motor disturbance, preventing spatial learning should still result in AP5-treated rats being impaired relative to controls.

However, it has also been claimed (Rudy and Keith, 1990) that if AP5 blocks spatial lcarning, the performance of AP5treated rats given spatial training should not differ from that of rats given aCSF but random placements of the platform. This argument would be valid if the water maze task really was a "pure" test of spatial learning in which no nonspatial strategies are available when the platform remains in a fixed location. In practice, even animals given hippocampal disruption - in which rapid spatial learning is severely and permanently impairedcan nevertheless learn to approach specific cues around the maze with extended training (Eichenbaum et al., 1990; Morris et al., 1990b). This would not occur with random placements of the platform. A more appropriate comparison, explored in Experiment 3, is to compare an AP5-treated group with rats given identical spatial training after hippocampal lesions.

\section{Sensorimotor control study}

Procedure. Animals were implanted with cithcr aCSF $(N=6)$ or $30 \mathrm{~mm}$ D-AP5 $(N=6)$ and tested in the water maze using 


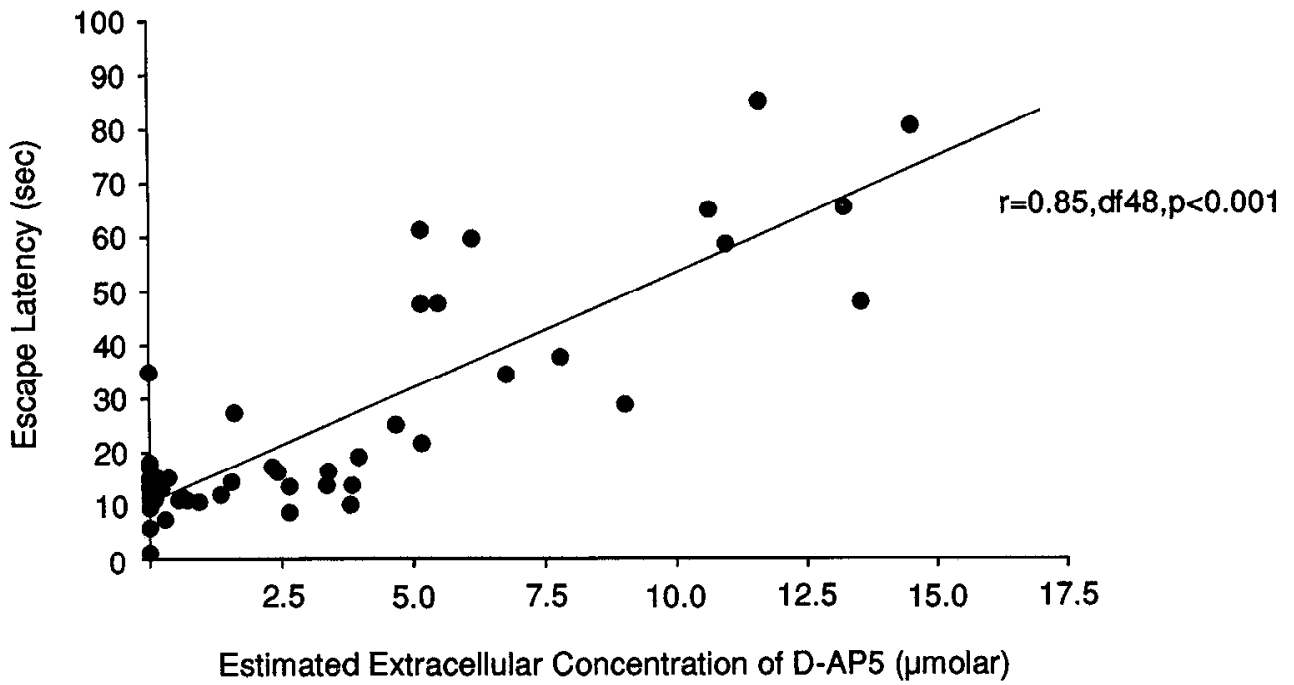

Figure 8. Relationship between mean escape latency across all 30 trials of spatial training and estimated extracellular concentration of D-AP5 in hippocampus. Points are plotted for the 49 rats from which behavioral, electrophysiological, microdialysis, and whole tissue samples were obtained. an identical procedure to that in the dose-response study with the sole exception that the platform was randomly relocated on each of the 30 trials of acquisition.

Results. During pretraining, the nonspatial aspects of the task were rapidly learned, with a decline in escape latencies across the $3 \mathrm{~d}$ of pretraining (Fig. $9 \mathrm{~A}$ ). Following surgery, both groups escaped on trial 1 of training with comparable latency $(\mathrm{CTL}=$ $70.4 \pm 20.4 \mathrm{sec}$; AP5 $=64.2 \pm 20.3 \mathrm{sec}$; Fig. $9 B$ ) and thereafter showed no significant change in escape latency across days ( $F$ $<1$; Fig. 9C). There were fluctuations from trial to trial across the 12 animals, but overall, mean escape latency changed little over the $5 \mathrm{~d}$ of random platform training, and the groups did not differ. During the transfer test, both groups spent an evenly distributed amount of time in each quadrant and no contrast in the ANOVA even approached significance (Fig. 9D).

\section{Hippocampal lesion study}

Procedure. A total of seven animals were first given pretraining according to the identical protocol as that used in the main experiment. They were then given bilateral hippocampal lesions using ibotenic acid (see Materials and Methods). Following a 2 week recovery period, 30 spatial training trials were given over
$5 \mathrm{~d}$ and the performance of this HPC group compared with that shown by the HC group in the main study (renamed HC-AP5 to avoid confusion).

Results. The extent of brain damage in the HPC group was an $85-90 \%$ removal of granule and pyramidal cells in the hippocampus along the entire dorsoventral axis. In most animals, the subiculum and entorhinal cortex was left entirely intact. In some animals, there was a slight difference between the size of the lesion on the right and left sides, but all animals had clear bilateral lesions. Histology from rats given similar lesions is shown in Jarrard (1989) and Morris et al. (1990b).

The main focus of this experiment was on performance during spatial training and the ensuing transfer test. Pretraining proceeded as usual (Fig. 10A). During postoperative spatial learning, the rats swam normally and used the platform as a refuge, displaying no sensorimotor abnormalities. However, they failed to learn its location.

On the first trial of day 1, the HPC group escaped in $56.3 \pm$ $13.9 \mathrm{sec}$ (see Fig. 10B). Thereafter, escape latency declined to a mean of $30.0 \pm 16.3 \mathrm{sec}$ on postoperative day 5 (Fig. 10C). Although apparently better during the early trials, it is striking that the HPC group and HC-AP5 group of the main study
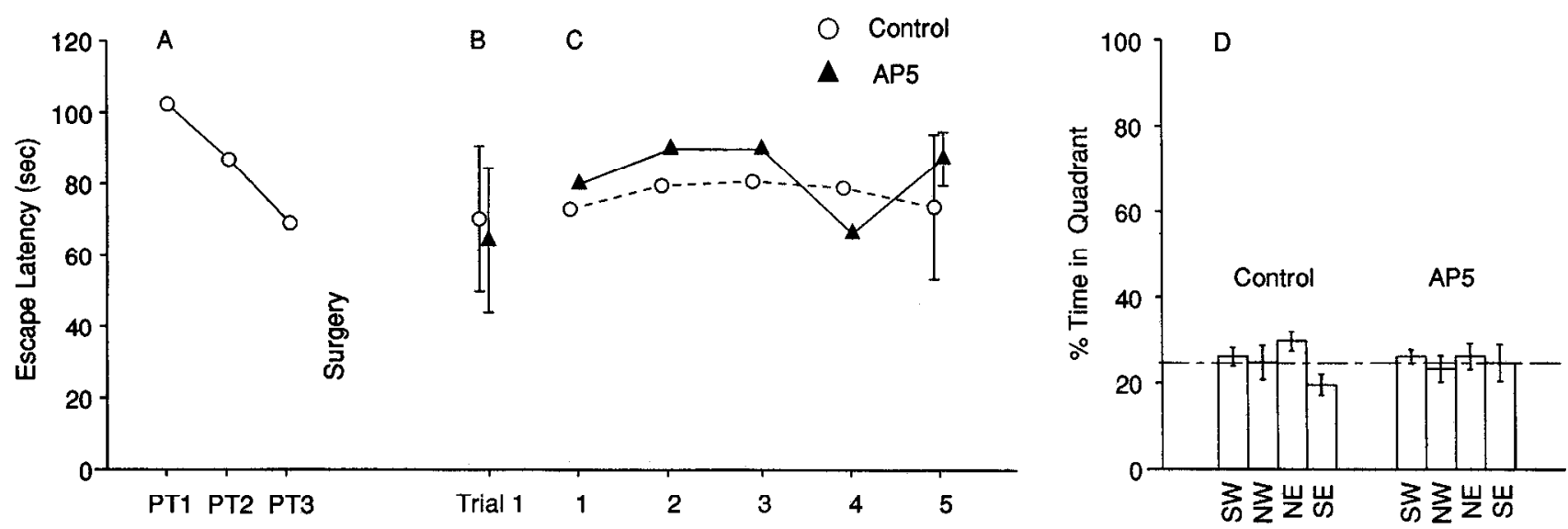

Figure 9. Experiment 2: escape latency ( $\mathrm{sec} \pm 1 \mathrm{SEM}$ ) of the rats in the random platform control study. $A$. Pretraining. $B$, Trial 1. $C$, Performance during $5 \mathrm{~d}$ (30 trials) of training in which the platform occupied a different spatial location on each trial. $D$, Random performance during the final transfer test. 

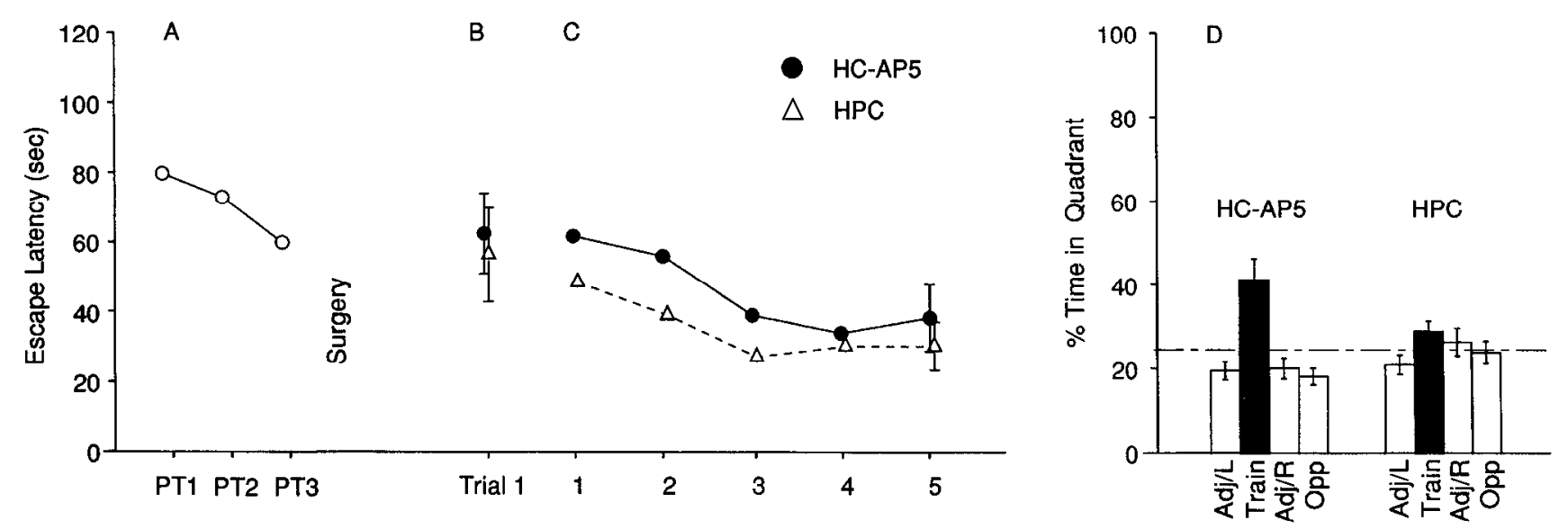

Figure 10. Experiment 3: escape latency ( $\mathrm{sec} \pm 1 \mathrm{SEM}$ ) of the rats given ibotenate hippocampal lesions (HPC) in comparison with group HC of the main dose-response study (renamed $H C-A P 5$ to avoid confusion). All rats reccivcd spatial training. $A$, Nonspatial pretraining. $B$, Trial 1 . $C$, Spatial training. $D$, Transfer test performance of the two groups. Although neither trend reached significance, note the crossover such that the HPC group tends to perform better on the escape latency measure but worse in the transfer test. See Discussion for comments on this crossover.

performed very similarly. A specific comparison of these groups showed that they did not differ $[F(1,21)=1.14 ; p>0.25]$.

During the final transfer test, the animals of the HPC group searched no more often in the training quadrant than in any other (Fig. 10D). The HC-AP5 group, however, appeared to perform better, but the trend shown in the groups by quadrants analysis did not reach significance $[F(2,63)=2.31 ; p>0.10]$.

\section{Discussion}

The aim of this series of experiments was to test more rigorously the hypothesis that activation of hippocampal NMDA receptors is required for spatial learning as first indicated by Morris et al. (1986). The main findings were (1) that chronic intraventricular infusion of D-AP5 caused a parallel dose-dependent impairment of spatial learning and LTP in vivo, (2) that intracerebral concentrations of AP5 just sufficient to block LTP caused a spatial learning impairment broadly comparable to that induced by ibotenate hippocampal lesions but failed to induce any measurable sensorimotor disturbance when spatial learning was prevented, (3) that the estimated extracellular concentration of AP5 in hippocampus was highly significantly correlated with wholetissue concentration but a factor of 30 times lower across a wide concentration range, and (4) that AP5 was released within the dialysate perfusate following the infusion of EGTA.

\section{Parallel dose-related impairment of spatial learning and LTP in vivo}

As outlined in the introduction, one important issue was whether there is a concentration of AP5 at which LTP is completely blocked but learning proceeds normally. No such conditions could be found. On the contrary, the correlational analyses established highly significant relationships between various measures of spatial learning and both hippocampal whole-tissue AP5 and the estimated hippocampal extracellular concentration. Indeed, the correlation between overall mean escape latency and extracellular AP5 concentration accounted for $71 \%$ of the variance $(r=0.84)$. This correlation is particularly important as it is the most comparable to conditions pertaining in experiments examining LTP in hippocampal slice preparations (extracellular concentration being comparable to bath concentration). The present results show, for the first time, that AP5 blocks both spatial learning and LTP in vivo across a concentration range comparable to that required to block LTP in area CAl in hippocampal slices in vitro (Harris et al., 1984). Specifically, the HC group had a whole-tissue AP5 concentration of $0.27 \mathrm{nmol} / \mathrm{mg}$ (Table 1) and an estimated extracellular AP5 concentration of $8.3 \mu \mathrm{M}$ (Fig. 6), resulting in only a $-1.2 \%$ change in mean slope function $30 \mathrm{~min}$ after the high-frequency train (Table 1). The animals in this group were severely impaired in learning (Fig. 3), although they appeared to have learned something about the escape platform's location (Fig. 4). Taken together, these data provide strong support for the now widely accepted view that the neural mechanisms underlying NMDAdependent hippocampal LTP play a role in spatial and perhaps other kinds of learning (McNaughton, 1983; Lynch and Baudry, 1984; Teyler and Discenna, 1987; Bliss and Lynch, 1988; Morris et al., 1990a). There are, however, several aspects of the behavioral results that require more detailed comments.

First, the MC and HC groups of the present study showed a latency impairment similar to that shown by AP5-treated rats in the Morris et al. (1986) study but better performance on the transfer test. In the Morris et al. (1986) study, animals were given a $40 \mathrm{~mm}$ racemic mixture of AP5 (equivalent to $20 \mathrm{~mm}$ D-AP5) but only 15 training trials prior to the no-platform transfer test. The better transfer test performance of the MC and $\mathrm{HC}$ groups in the present study, where training continued for 30 trials, probably reflects their longer training period and thus indicates that AP5 slows the rate of spatial learning rather than blocking learning completely. Further comparisons between these studies are difficult, as a $30 \mathrm{sec}$ ITI between the six daily trials was used in the present work while a $4 \mathrm{hr}$ ITI was used between the three daily trials in the Morris et al. (1986) study (cf. Keith and Rudy, 1990).

$\Lambda$ second point concerning the learning impairment is that, while the performance of the $\mathrm{HC}$ group was broadly comparable to that shown by HPC animals trained according to an identical procedure, an interesting crossover in performance was observed between the acquisition phase and the transfer test. Whereas the $\mathrm{HC}$ group showed a nonsignificant trend toward escaping more slowly than the HPC group during acquisition, it also showed a trend toward better performance in the transfer test. There are two possible explanations for this crossover. First, 
during complex forms of learning, NMDA receptor activation will be only part of the pattern of neuronal activity occurring in hippocampus. In the case of the HPC animals, all the cells are destroyed, whereas in AP5-treated animals, only NMDA receptors are inactivated. It might therefore be the case that the AP5-treated animals are able to process some information about the task via AMPA receptor-mediated excitatory neurotransmission and activation of other neurotransmitter systems. Put another way, blocking synaptic plasticity may not mirror all aspects of the hippocampal lesion-induced behavioral "syndrome." The second interpretation of this crossover effect is that the AP5-treated animals' poor performance during acquisition, particularly during the early stages, could have been due to some cryptic sensorimotor or motivational impairment of which no overt signs were displayed. This is an important issue to consider, as the VHC group did show obvious signs of such effects and there have been several reports in the literature that NMDA receptor antagonists cause motor deficits (Compton et al., 1987; Koek et al., 1987; Contreras et al., 1988; Leung and Desborough, 1988; Tricklebank et al., 1989) and sensory impairments (Salt, 1986; Sillito et al., 1990) and have analgesic properties (Dunn et al., 1989). Unfortunately, the possibility that the apparent learning impairment is secondary to a druginduced sensorimotor disturbance is an issue far from easy to address (see Morris, 1988; Mondadori et al., 1989; Keith and Rudy, 1990). There are, however, several grounds to doubt this possibility - at least up to intrahippocampal concentrations of AP5 just sufficient to block LTP (but not necessarily at higher concentrations). For example, the present data show that no strictly motor impairment remains when spatial learning is prevented by random placements of the escape platform. In a similar vein, previous work (Morris, 1989; Experiment 3) has shown that certain measurable sensorimotor disturbances induced by AP5 in the water maze apparatus can be significantly reduced by giving nonspatial pretraining without affecting the magnitude of the learning impairment. Taken together, these observations suggest that the AP5-induced learning impairment and its sensorimotor "side effects" are potentially dissociable. A further point is that AP5 has no effect on visual pattern discrimination learning in the water maze, a type of learning unaffected by aspiration hippocampal lesions (Morris et al., 1986), irrespective of whether it is infused by an intraventricular (Morris, 1989; Experiment 2) or intracortical (Butcher et al., 1991) route. Spared visual pattern discrimination learning indicates that, at concentrations sufficient to impair spatial learning, AP5 is probably not causing a gross disturbance of vision - although more subtle deficits in acuity or contrast sensitivity (Fox et al., 1990) cannot yet be ruled out. It nevertheless remains true that pronounced sensorimotor disturbances were observed in the VHC group. This may be explained with reference to the cerebral distribution of AP5 following intraventricular infusion. The rationale for using intraventricular infusion in this and earlier studies is that the adjacent hippocampus can be continuously infused with relatively high concentrations of AP5 but spared from any mechanical damage caused by the presence of a cannula in the tissue. AP5 tissue concentration declines gradually from the point of infusion in the ventricles (Butcher et al., 1991). Thus, it might be the case that as AP5 concentration rises significantly above the level required to block LTP (e.g., in the VHC group), it also begins to reach concentrations in other brain areas (e.g., thalamus, cortex, striatum) at which significant NMDA receptor blockade is occurring and nonhippocampal cerebral distur- bances begin to take effect. Thus, while not denying that interpretative difficulties arise with intraventricular infusion that can be obviated by local infusion (Morris et al., 1989; Miserindino et al., 1990), it seems most parsimonious to interpret the present spatial learning impairment as reflecting a blockade of hippocampal NMDA receptors.

A third aspect of the behavioral results is that the escape latencies of the AP5-treated HC group were substantially shorter than those of both the aCSF and the AP5 groups in the random platform condition (Experiment 2). According to Rudy and Keith (1990), such a finding indicates that some spatial learning must have been occurring despite an AP5 concentration sufficient to block LTP. The problem with this argument is that the HCAP5 group did not differ substantially from an HPC group that showed little evidence of spatial learning in the transfer test conducted after 30 trials. More extensive training of HPC groups can lead to a measurable spatial bias to the training quadrant (Morris et al., 1990b), but whether this reflects true allocentric spatial learning or an ambiguity of this version of the water maze lask (e.g., approach to a specific extramaze cue) is unclear.

A fourth problem concerning the behavioral deficit is the failure of the AP5-treated animals to gain weight during the week following minipump implantation. This problem was first noted by Tonkiss et al. (1988), who also found that AP5 impaired performance on a differential reinforcement at low rate (DRL) schedule. In the present study, the fact that the aCSFtreated animals also failed to gain weight suggests that this may be partially due to the presence of the cannula and/or the pumping of a solution into the ventriclc. While there may also be an effect on weight gain due to AP5 alone, it should be recognized that this trend failed to reach significance. Further, as the aCSFtreated rats were behaviorally indistinguishable from the unoperated control rats (and thus combined into a single CTL group in most analyses), it seems unlikely that the failure to gain weight was a major causative factor in the dose-related impairment of learning. Analogous arguments were put forward by Tonkiss et al. (1988) to draw the same conclusion with respect to the independence of the DRL impairment from that responsible for the failure to gain weight.

\section{Other correlates of the variation in AP5 concentration}

That AP5 caused a dose-dependent blockade of induction of LTP was to be expected based on the findings of Harris et al. (1984). However, an unexpected finding was that there also appcarcd to bc a decline in PTP/STP - specifically, a dose-related reduction in the maximal amount of PTP/STP and an increase in its rate of decay. PTP is thought to reflect increased presynaptic release of transmitter as a consequence of highfrequency activation and mechanistically related to paired-pulse potentiation (McNaughton, 1982). However, AP5 does not affect paired-pulse potentiation in the hippocampal slice (Harris and Cotman, 1983) and thus should not affect PTP. An alternative interpretation of the present findings is that the accelerated short-term decay of field potential slope was actually an early and short-term phase of LTP (i.e., STP). A recent study of the time course of the development and expression of LTP (Gustaffson et al., 1989) indicates that it grows over about 30 sec to an initial maximum and then declines over the course of the next $60-90 \mathrm{sec}$. It is possible that AP5 interacts with these temporal dynamics. The present study did not use tetanization trains likely to induce much PTP (three trains of 33 pulses at $400 \mathrm{~Hz}$ separated at intervals of $10 \mathrm{sec}$ ) or recording arrange- 
ments suitable for monitoring PTP accurately (low-frequency test stimulation at $0.1 \mathrm{~Hz}$ ). Clearly, it would be valuable to reexamine whether AP5 affects PTP or the early phases of LTP (STP) using morc suitable stimulating and recording arrangements.

AP5 caused no change in amino acid levels in either hippocampal whole-tissue or dialysate samples apart from causing a dose-dependent increase in the whole-tissue levels of valine. The basis of this effect is unclear. The lack of any change in the five other amino acids measured (Asp, Glu, Gln, Tau, and Ala) suggests that chronic infusion of AP5 does not cause any primary effect on amino acid catabolism. The failure to see any relationship between the dialysate levels of glutamate and the amount of LTP induced is, arguably, inconsistent with Bliss and Lynch's (1988) evidence that LTP is associated with increased presynaptic transmitter release. However, glutamate is taken up rapidly into both neurons and glia (Nicholls and Attwell, 1990), and it should be borne in mind that the microdialysis samples were taken at least $1.5 \mathrm{~h}$ after the tetanic stimulation.

\section{Discrepancy between whole-tissue and estimated extracellular concentration of AP5}

One of the most intriguing findings of this study is the 30 -fold discrepancy between the whole-tissue and estimated extracellular concentrations of AP5. The further finding that infusion of EGTA causes a massive release of AP5 into the dialysate perfusate, quite apart from being an interesting observation in its own right, underlines the existence of this whole-tissue/extracellular discrepancy.

The following calculations are relevant to understanding this phenomenon. Consider an animal with a minipump containing a $30 \mathrm{~mm}$ solution of D-AP5 pumping at a rate of $0.5 \mu \mathrm{l} / \mathrm{hr}$. If the animal is killed after $10 \mathrm{~d}$, a total of $10(\mathrm{~d}) \times 24(\mathrm{hr}) \times 0.5$ $\times 10^{-6}$ (pumping rate) $\times 30 \times 10^{-3}$ (concentration) mol of AP5 will have been infused into the brain, that is, $3.60 \mu \mathrm{mol}$. Calculations bascd on calibration functions rclating wholc-tissuc concentration to minipump concentration indicate that 0.27 $\mathrm{nmol} / \mathrm{mg}$ wet weight is found in animals who have had $30 \mathrm{~mm}$ AP5 in their minipumps. As the weight of the forebrain is approximately $1.5 \mathrm{gm}$, the actual amount of AP5 within it can be no greater than $1500 \times 0.27 \mathrm{nmol}$, that is, $0.41 \mu \mathrm{mol}$. Thus, at death, only $11 \%$ of the AP5 pumped into the brain remains, indicating that $89 \%$ has left the brain or been metabolized. Now consider accumulation of the residual AP5 within the ventricular CSF. The estimated volume of ventricular space in the brain is $200 \mu \mathrm{l}$. On the basis of the previous calculations, $11 \%$ of the AP5 infused into the brain should accumulate in ventricular fluid such that, at steady state, the rate at which AP5 comes in via the minipumps should be equal to the rate at which it leaves the brain. This steady state may be reached quite quickly but, in the absence of pharmacokinetic information about the ratc at which the drug leaves the brain, can only be calculated by assuming that the situation at death is the steady state. Thus, if all the residual AP5 remains in the interstitial compartment, approximately $0.41 \mu \mathrm{mol}$ of AP5 should be present in $200 \mu \mathrm{l}$ of CSF, corresponding to an extracellular concentration of 2 mM. However, this outcome clearly does not occur, for the dialysis and whole-tissue measures have established that the estimated extracellular concentration is approximately 30 times lower than the tissue value, that is, at $8 \mu \mathrm{M}-\mathrm{a}$ concentration that should be and was sufficient to block LTP effectively. The potential inaccuracy of these calculations must be recognized, but they do indicate that some uptake or trapping of AP5 must have taken place, thereby removing it from the only compartment from which it is likely to have access to synaptic NMDA receptors.

Biochemical experiments have established that D-AP5 neither inhibits the uptake of ${ }^{3} \mathrm{H}-\mathrm{L}$-glutamate nor is ${ }^{3} \mathrm{H}-\mathrm{D}-\mathrm{AP} 5$ itself taken up on the high-affinity glutamate uptake carrier. However, J. C. Watkins' suggestion (personal communication) that AP5 might be "trapped" to the extracellular membrane by some $\mathrm{Ca}^{2+}$-dependent mechanism was upheld by the finding that infusion of EGTA (in a $\mathrm{Ca}^{21}$-free buffer) caused a release of AP5. As it cannot be established how far the EGTA spreads from the microdialysis tubing, nor over what volume the dialysis tubing samples ecf, too much should not be made of the observation that EGTA caused only a sevenfold increase in AP5 in the perfusate when the extracellular/whole-tissue ratio was 1:30. The fact that release occurs at all is the pertinent point. Other evidence for trapping comes from cortical slice experiments. Bear et al. (1990) observed a time-dependent accumulation of ${ }^{3} \mathrm{H}-\mathrm{D}-\mathrm{AP} 5$ in visual cortex slices bathed in known concentrations of ${ }^{3} \mathrm{H}-\mathrm{D}-\mathrm{AP} 5$. Their results indicated that this accumulation declined after 18-24 hr, but whether this reflects a saturation of the "trapping" mechanism or the death of the cortical slices remains unclear. Aspects of our own data indicate that the linear function relating extracellular to whole-tissue concentration might have been breaking down at high concentrations (with estimated extracellular concentration increasing more rapidly for a given increase in whole-tissue concentration), but there were too few data on which to base a firm conclusion about the saturation of trapping. Clearly, there are a range of questions about this trapping phenomenon (time course, drug specificity, and mechanism) that would be interesting to explore further.

\section{Conclusion}

In summary, the results of these experiments provide a firmer foundation for the hypothesis that hippocampal NMDA receptors play a role in spatial learning. This hypothesis must be qualified in two important respects. First, it seems unlikely that the necessity for NMDA receptor activation is in any way specific to spatial learning. AP5 and other competitive antagonists impair nonspatial DRL performance (Tonkiss et al., 1988), working memory (Danysz el al., 1989; Ward et al., 1990), fearpotentiated startle (Miserindino et al., 1990), and taste-potentiated odor-aversion learning (Crooks et al., 1989). As pointed out elsewhere (Morris et al., 1990a), the exact role that NMDA receptor activation plays in learning depends critically on both the anatomical circuits of which they are a part and the electrophysiological system dynamics. Second, NMDA receptors are not learning receptors per se. Rather, they are molecular devices that detect a conjunction between presynaptic activity and sustained postsynaptic depolarization. This physiological property enables them to perform a myriad of different functions in different neuronal circuits, including experience-dependent self organization (McDonald and Johnston, 1990; Singer, 1990), sensory transduction (Daw et al., 1990; Sillito et al., 1990), and the coordination of rhythmic movements (Dale, 1989). However, subject to these qualifications and constraints, the present results provide strong support for the hypothesis that hippocampal NMDA receptor activation, via a mechanism activated during the existence of the most prominent form of LTP, plays a crucial role in certain types of learning. 


\section{References}

Bear MF, Cooper LN, Ebner FF (1987) A physiological basis for a theory of synapse modification. Science $237: 42-48$.

Bear MF, Kleinschmidt A, Gu Q, Singer W (1990) Disruption of experience-dependent modifications in the striate cortex by infusion of an NMDA receptor antagonist. J Neuroscience 10:909-925.

Benveniste H (1989) Brain microdialysis. J Neurochem 52:1667-1679.

Bliss TVP, Lynch MA (1988) Long-term potentiation of synaptic transmission of the hippocampus: properties and mechanisms. In: Synaptic potentiation of the brain: a critical analysis (Landfield PW, Deadwyler SA, eds). New York: Liss.

Butcher SP, Hamberger A, Morris RGM (1991) Intracerebral distribution of D,L-2-amino-phosphonopentanoic acid (AP5) and the dissociation of different types of learning. Exp Brain Res 83:521-526.

Castro CA, Silbert LH, McNaughton BL, Barnes CA (1989) Recovery of spatial learning deficits after decay of electrically induced synaptic enhancement in the hippocampus. Nature 342:545-548.

Collingridge GL, Kehl SJ, McLennan H (1983) Excitatory amino acids in synaptic transmission in the Schaeffer collateral-commissural pathway of the rat hippocampus. J Physiol (Lond) 334:33-46.

Compton RP, Contreras PC, O'Donoghue TL, Monaghan JB (1987) The $N$-methyl-D-aspartate antagonist, 2-amino-7-phosphonohaptanoate produces phencyclidine-like behavioural effects in rats. European J Pharmacol 136:133-134.

Contreras PC, Contreras ML, O'Donoghue TL, Lair CC (1988) Biochemical and behavioural effects of sigma and PCP ligands. Synapse $2: 240-243$.

Crooks EB, Robinson GS, Hatfield TJ, Graham PW, Gallagher $M$ (1989) Intraventricular administration of the NMDA antagonist APV disrupts learning of an odour aversion that is potentiated by taste. Soc Neurosci Abstr 15:464.

Dale N (1986) Excitatory synaptic drive for swimming mediated by amino acid receptors in the lamprey. J Physiol (Lond) 6:2668-2675.

Dale $N$ (1989) The role of NMDA receptors in synaptic integration and the organisation of complex neural patterns. In: The NMDA receptor (Watkins JC, Collingridge GL, eds). Oxford: Oxford UP.

Danysz W, Wroblewski JT, Costa E (1988) Learning impairment in rats by $N$-methyl-D-aspartate receptor antagonists. Neuropharmacology 27:653-656.

Daw N, Fox K, Sato H (1990) The effect of varying stimulus intensity on NMDA receptor activity in cat visual cortex. J Physiol 420:46P.

Dingledine R (1983) $N$-Methyl-aspartate activates voltage-dependent calcium conductance in rat hippocampal pyramidal cells. J Physiol (Lond) 343:385-405.

Dunn RW, Corbett R, Fielding S (1989) Effects of 5-HT $\mathrm{H}_{1 \mathrm{~A}}$ receptor agonists and NMDA receptor antagonists in the social interaction test and the elevated plus maze. Eur J Pharmacol 169:1-10.

Eichenbaum H, Stewart C, Morris RGM (1990) Hippocampal representation in place learning. J Neurosci 10:3531-3542.

Engberg I, Flatman JA, Lambert JDC (1979) The actions of excitatory amino acids on motorneurones in the feline spinal cord. J Physiol (Lond) 288:227-261.

Fox K, Sato H, Daw N (1989) The location and function of NMDA receptors in cat and kitten visual cortex. J Neurosci 9:2443-2454.

Fox K, Sato H, Daw N (1990) The effect of varying stimulus intensity on NMDA-receptor activity in cat visual cortex. J Neurophysiol 64 : $1413-1428$.

Gustaffson B, Asztely F, Ilanse E, Wigstrom II (1989) Onset characteristics of long-term potentiation in the guinea-pig hippocampal CA1 region in vitro. Eur J Neurosci 1:382-394.

Harris EW, Cotman CW (1983) Effects of acidic amino-acid antagonists on paired-pulse potentiation at the lateral perforant path. Exp Brain Res 52:455-460.

Harris EW, Ganong AH, Cotman CW (1984) Long-term potentiation in the hippocampus involves activation of $N$-methyl-D-aspartate receptors. Brain Res 382:174-177.

Jarrard LE (1989) On the use of ibotenic acid to lesion selectively different components of the hippocampal formation. J Neurosci Methods 29:251-259.

Keith JR, Rudy JW (1990) Why NMDA-receptor-dependent longterm potentiation may not be a mechanism of learning and memory: reappraisal of the NMDA-receptor blockade strategy. Psychobiology 18:251-257.

Kleinschmidt A, Bear MF, Singer W (1987) Blockade of NMDA re- ceptors disrupts experience dependent plasticity in kitten striate cortex. Science 238:355-358.

Koek W, Woods JH, Ornstein P (1987) A simple and rapid method for assessing similarities among directly observable bchavioural effects of drugs: PCP-like effects of 2-amino-5-phosphonvalerate in rats. Psychopharmacology 91:297-304.

Leung LWS, Desborough KA (1988) APV, an $N$-methyl-D-aspartate receptor antagonist, blocks the hippocampal theta rhythm in behaving rats. Brain Res 463:148-152.

Lindroth P, Hamberger A, Sandberg M (1985) Liquid chromatographic determination of amino acids after recolumn fluorescence derivatisation. In: Neuromethods 3: amino acids (Boulton AA, Baker GB, Wood JD, eds). Clifton, NJ: Humana.

Lynch G, Baudry M (1984) The biochemistry of memory: a new and specific hypothesis. Science 224:1057-1063.

MacDonald JF, Porietris AV, Wojtowicz JM (1982) L-Aspartic acid induces a region of negative slope conductances in the current-voltage relationship of culturcd spinal cord neurons. Brain Res 237:248-253.

Mayer ML, Westbrook GL (1987) The physiology of excitatory amino acids in the vertebrate central nervous system. Progress Neurobiol 28:197-276.

Mayer ML, Westbrook GL, Guthrie PB (1984) Voltage dependent block by magnesium of NMDA responses in spinal cord neurones. Nature 309:261-263.

McDonald JW, Johnston MV (1990) Physiological and pathophysiological roles of excitatory amino acids during central nervous system development. Brain Res Rev 15:41-70.

McNaughton BL (1983) Activity dependent modulation of hippocampal synaptic efficacy: some implications of memory processing. In: Neurobiology of the hippocampus (Siefert W, ed). London: Academic.

McNaughton BL, Barnes CA, Rao G, Baldwin J, Rasmussen M (1986) Long-term cnhancement of hippocampal synaptic transmission and the acquisition of spatial information. J Neurosci 6:563-571.

Miserindino MJD, Sananes CB, Melia KR, Davis M (1990) Blockade of fear-potentiated startle by $N$-methyl-D-aspartate antagonists infused into the amygdala. Nature 345:716-718.

Monaghan DT, Cotman CW (1985) Distribution of $N$-methyl-D-aspartate-sensitive $\mathrm{L}-\left[{ }^{3} \mathrm{H}\right]$ glutamate-binding sites in rat brain. J Neurosci 5:2909-2919.

Monaghan DT, Holets VR, Toy DW, Cotman CW (1983) Anatomical distributions of four pharmacologically distinct ${ }^{3} \mathrm{H}$-L-glutamate binding sites. Nature 306:176-179.

Mondadori C, Weiskrantz L, Buerki H, Petschke F, Fagg GE (1989) NMDA receptor antagonists can enhance or impair learning performance in animals. Exp Brain Res 75:449-456.

Morris RGM (1981) Spatial localisation does not depend on the presence of local cues. Learn Motiv 12:239-260.

Morris RGM (1984) Developments of a water-maze procedure for studying spatial learning in the rat. J Neurosci Methods 11:47-60.

Morris RGM (1988) Elements of a hypothesis concerning the participation of hippocampal NMDA receptors in learning. In: Excitatory amino acids in health and disease (Lodge D, ed), pp 297-320. Chichester: Wiley.

Morris RGM (1989) Synaptic plasticity and learning: selective impairment of learning in rats and blockade of long-term potentiation in vivo by the $N$-methyl-D-aspartate receptor antagonist, AP5. J Neurosci 9:3040-3057.

Morris RGM, Andersen E, Lynch GS, Baudry M (1986) Selective impairment of learning and blockade of long-term potentiation by an $N$-methyl-D-aspartate receptor antagonist, APV. Nature 319:774-776.

Morris RGM, Halliwell RF, Bowery N (1989) Synaptic plasticity and learning II: do different kinds of plasticity underly different kinds of learning? Neuropsychologia 27:41-59.

Morris RGM, Davis S, Butcher SP (1990a) Hippocampal synaptic plasticity and NMDA receptors: a role in information storage? Philos Trans R Soc Lond [Biol] 329:187-204.

Morris RGM, Schenk F, Tweedie F, Jarrard LE (1990b) Ibotenate lesions of hippocampus and/or subiculum: dissociating components of allocentric spatial learning. Eur J Neurosci 2:1016-1028.

Nicholls D, Attwell D (1990) The release and uptake of excitatory amino acids. Trends Pharmacol Sci 11:462-468.

Nowak L, Bregestovski P, Ascher P (1984) Magnesium gates glutamate-activated channels in mouse central neurones. Nature 307:426465 .

O'Keefe J, Nadel L (1978) The hippocampus as a cognitive map. Oxford: Oxford UP. 
Olton DS, Becker JT, Ilandleman GE (1979) Hippocampus, space and memory. Behav Brain Sci 2:313-365.

Rudy JR, Keith JR (1990) Why NMDA-receptor-dependent longterm potentiation may not be a learning and memory mechanism, or is it Memorex? A reply to Morris, Gallagher and Staubli. Psychobiology 18:269-272.

Salt TE (1986) Mediation of thalamic sensory input by both NMDA receptors and non-NMDA receptors. Nature 322:263-265.

Sandberg M, Butcher SP, Hagberg H (1986) Extracellular overflow of neuroactive amino acids during severe insulin induced hypoglycemia: in vitro microdialysis of the rat hippocampus. J Neurochem 47:178184.

Sharp PE, McNaughton BL, Barnes CA (1985) Enhancement of hippocampal field potentials in rats exposed to a novel, complex environment. Brain Res 339:361-365.

Sillito A, Murphy PC, Salt TE, Moody CI (1990) The dependence of retino-geniculate transmission in the cat on NMDA receptors. J Neurophysiol 63:347-355.
Singer W (1990) Ontogenetic self-organisation and learning. In: Brain organisation and memory: cells, systems and circuits (McGaugh JL, Weinberger NM, Lynch G, eds), pp 211-233. Oxford: Oxford UP. Squire LR (1987) Memory and brain. New York: Oxford UP.

Teyler TJ, Discenna P (1987) Long-term potentiation. Annu Rev Neurosci $10: 131-161$.

Tonkiss J, Morris RGM, Rawlins JNP (1988) Intra-ventricular infusion of the NMDA antagonist AP5 impairs performance on a nonspatial operant DRL task in the rat. Exp Brain Res 73:181-188.

Tricklebank MD, Singh L, Oles RJ, Wong EHF, Iversen SD (1989) The behavioural effects of MK-801: a comparison with antagonists acting noncompetitively and competitively at the NMDA receptor. Eur J Pharmacol 167:127-135.

Ward L, Mason SE, Abraham WC (1990) Effects of the NMDA antagonists, CPP and MK-801 on the radial arm maze performance in rats. Pharmacol Biochem Behav 35:785-790. 